\title{
Pathological response of cavernous malformations following radiosurgery
}

\author{
Samuel S. Shin, MD, PhD, ${ }^{1}$ Geoffrey Murdoch, MD, PhD, ${ }^{2}$ Ronald L. Hamilton, MD, ${ }^{2}$ \\ Amir H. Faraji, MD, PhD, ${ }^{1}$ Hideyuki Kano, MD, PhD, ${ }^{1}$ Nathan T. Zwagerman, MD, ${ }^{1}$ \\ Paul A. Gardner, MD, ${ }^{1}$ L. Dade Lunsford, MD, ${ }^{1}$ and Robert M. Friedlander, MD1 \\ Departments of ${ }^{1}$ Neurological Surgery and ${ }^{2}$ Pathology, University of Pittsburgh Medical Center, Pittsburgh, Pennsylvania
}

\begin{abstract}
OBJECT Stereotactic radiosurgery (SRS) is a therapeutic option for repeatedly hemorrhagic cavernous malformations (CMs) located in areas deemed to be high risk for resection. During the latency period of 2 or more years after SRS, recurrent hemorrhage remains a persistent risk until the obliterative process has finished. The pathological response to SRS has been studied in relatively few patients. The authors of the present study aimed to gain insight into the effect of SRS on CM and to propose possible mechanisms leading to recurrent hemorrhages following SRS.
\end{abstract}

METHODS During a 13-year interval between 2001 and 2013, bleeding recurred in 9 patients with CMs that had been treated using Gamma Knife surgery at the authors' institution. Microsurgical removal was subsequently performed in 5 of these patients, who had recurrent hemorrhages between 4 months and 7 years after SRS. Specimens from 4 patients were available for analysis and used for this report.

RESULTS Histopathological analysis demonstrated that vascular sclerosis develops as early as 4 months after SRS. In the samples from 2 to 7 years after SRS, sclerotic vessels were prominent, but there were also vessels with incomplete sclerosis as well as some foci of neovascularization.

CONCLUSIONS Recurrent bleeding after SRS for CM could be related to incomplete sclerosis of the vessels, but neovascularization may also play a role.

http://thejns.org/doi/abs/10.3171/2014.10.JNS14499

KEY WORDS cavernous malformation; stereotactic radiosurgery; brain hemorrhage

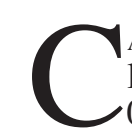

AVERNOUS malformations (CMs) are angiographically occult, low-flow vascular lesions that are found in $0.4 \%-0.8 \%$ of the general population. ${ }^{8,22,26}$ Familial $\mathrm{CMs}$ can be associated with mutations in the $C C M$ and KRIT genes leading to vasculogenesis. ${ }^{3,16,17}$ Bleeding rates for clinically unruptured CMs range from $1 \%$ to $2 \%$ per year, ${ }^{12,14}$ although MRI always shows old blood deposition in the malformation. After an initial clinically recognized hemorrhage, the risk of additional hemorrhages increases to $4 \%$ per year and can be as high as $34 \%$ per year after 2 or more bleeds..$^{14,15}$ When located in accessible brain regions, CMs can be microsurgically removed. ${ }^{7,9,28,29,35}$ However, hemorrhagic CMs located in deep-seated brain regions without a pial or ependymal access corridor are technically challenging and associated with significant complication rates. ${ }^{4,20,25,36}$ Stereotactic radiosurgery (SRS) can be a treatment option for such CMs..$^{13,19,21}$

Although the recurrent hemorrhage rate of CMs following SRS has been reported, ${ }^{11,13,19}$ relatively few publications describe the histological response of CM after SRS.10,23,34 The studies that do exist are case reports and small case series describing obliteration and scarring of CM tissue after radiosurgery. Briefly, Nyáry et al. described the case of a CM treated with SRS resulting in fibrosis of the CM. ${ }^{23}$ Similarly, Tu et al. found hyalinization, collagen formation, and partial luminal occlusion of CMs after SRS in

ABBREVIATIONS AVM = arteriovenous malformation; bFGF = basic fibroblast growth factor; $\mathrm{CM}=$ cavernous malformation; MMP-9 = matrix metallopeptidase 9; SRS = stereotactic radiosurgery; VEGF = vascular endothelial growth factor.

ACCOMPANYING EDITORIAL See pp 935-937. DOI: 10.3171/2014.10.JNS142305.

SUBMITTED March 8, 2014. ACCEPTED October 7, 2014.

INCLUDE WHEN CITING Published online June 19, 2015; DOI: 10.3171/2014.10.JNS14499.

DISCLOSURE The authors report no conflict of interest concerning the materials or methods used in this study or the findings specified in this paper. Dr. Gardner is a consultant for Integra LifeSciences. Dr. Lunsford is a consultant and stockholder in AB Elekta, Stockholm, Sweden. 
3 patients $;{ }^{34}$ however, obliteration of the luminal area was less drastic in CMs than in arteriovenous malformations (AVMs). Gewirtz et al. found fibrosis of vascular channels, fibrinoid necrosis, and ferrugination in 8 patients with CMs treated with SRS. ${ }^{10}$ Tissue samples in these studies were obtained from resections following SRS or conventional irradiation. The limitation in an analysis of resected samples is the potential bias in evaluating only the CMs that do not respond to SRS.

According to previous studies, after SRS, between 8\% and $17 \%$ of patients require delayed resection because of continued hemorrhagic events..$^{11,13,19}$ To better understand the causes of repeated bleeding of CMs following SRS, we performed a histopathological analysis of the resected specimens in 4 patients who had undergone delayed microsurgery.

\section{Methods}

The University of Pittsburgh institutional review board approved this retrospective analysis. During the interval between 2001 and 2013, 9 cases of CM had recurrent bleeding after Leksell Gamma Knife surgery (median 31 months, range 6-57 months). Patients in 5 of these cases underwent subsequent resection of their CMs. One tissue sample obtained during microsurgical resection was small and insufficient for analysis. Thus, CMs from the remaining 4 patients were used to perform detailed histopathological analyses. The intervals between SRS and microsurgery were 4 months, 2.5 years, 3 years, and 7 years (Table 1).

\section{Histology and Immunohistochemistry}

Formalin-fixed paraffin-embedded 4- to 6- $\mu$ m sections were stained with H \& E. Gomori's Modified Iron Stain and Masson's trichrome stain were used to evaluate blood vessel walls and demonstrate hemosiderin. Immunohistochemistry for vascular endothelial growth factor (VEGF; mouse monoclonal antibody, 1:100, Millipore), basic fibroblast growth factor (bFGF; Biogenex ready-to-use kit), and matrix metallopeptidase 9 (MMP-9; 1:50, GeneTex) was performed on 4- to 6- $\mu \mathrm{m}$ tissue sections. Pretreatment of sections for VEGF and MMP-9 consisted of antigen retrieval citrate buffer $(1 \times, \mathrm{pH} 6$, Biogenex) in a steam chamber for 20 minutes and cooling for 20 minutes. No pretreatment was used for the bFGF. Each primary anti- body was incubated for 45 minutes at room temperature in a humid slide chamber. Goat anti-mouse secondary antibody (Dako) was used on VEGF and MMP-9 (1:200) for 30 minutes. The EnVision system anti-mouse antibody (Dako) was used for 30 minutes for bFGF. The Vectastain ABC kit (Vector Labs) was applied to VEGF and MMP9 for an additional 30 minutes for biotinylated enzyme activity. Sections were subsequently developed using the Vectastain ABC kit with the NovaRED peroxidase substrate kit (Vector Labs) and counterstained with Mayer's hematoxylin and lithium carbonate solution.

\section{Illustrative Cases}

The 4 patients analyzed in this study had samples from resections performed at different periods following SRS. These samples were also obtained from 4 different anatomical locations: right thalamus/midbrain region, right pons, left mesial temporal lobe, and left pons.

\section{Case 1}

History and Examination

A 23-year-old female presented with acute-onset facial and oral numbness accompanied by mild frontal headache. Computed tomography studies of her brain demonstrated a $2 \times 2-\mathrm{cm}$ acute right thalamic hemorrhage that extended into the midbrain. Magnetic resonance imaging findings were compatible with a hemorrhagic CM. Given the lesion location and after discussing different options, observation was elected. The patient presented 6 months later with diplopia and left paresis, associated with further hemorrhage on MRI. She was discharged after stabilization and returned 2 months later for SRS.

\section{Operation and Postoperative Course}

The patient underwent Gamma Knife surgery: a 28.2Gy maximum dose and 14-Gy margin dose delivered to a $2.33-\mathrm{cm}^{3}$ malformation in a single session. Three months after SRS the patient reported worsening headaches, and repeat MRI demonstrated a new hemorrhage. She again improved over the course of 48 hours with no neurological deficits. One month later she experienced another acuteonset headache, which progressed to left paresis, with an increase in the hemorrhage to $2.6 \mathrm{~cm}^{3}$ (Fig. 1A). She underwent microsurgical removal of the $\mathrm{CM}$ via a right subtemporal craniotomy, and the CM was resected en bloc.

TABLE 1. Clinical details and pathological findings in 4 cases

\begin{tabular}{clccl}
\hline $\begin{array}{c}\text { Case } \\
\text { No. }\end{array}$ & Sample Location & $\begin{array}{c}\text { Resection } \\
\text { Time }\end{array}$ & Clinical Presentation & Pathology \\
\hline 1 & Rt thalamus, midbrain & 4 mos & $\begin{array}{c}\text { Lt-sided paresis, It-sided anesthesia of } \\
\text { face \& body, It blurry vision, frontal } \\
\text { headache }\end{array}$ & $\begin{array}{c}\text { Sclerosis \& partial luminal narrowing in a minority of vessels, } \\
\text { large luminal diameter w/ thin walls in majority of vessels, } \\
\text { small organizing vessels in areas of previous hemorrhage }\end{array}$ \\
\hline 2 & Rt pons & 2.5 yrs & $\begin{array}{c}\text { Lt-sided paresis, It-sided anesthesia of } \\
\text { face \& body, rt CN VI \& VIl palsies }\end{array}$ & $\begin{array}{c}\text { Sclerosis \& partial narrowing of most vessels; occasional scle- } \\
\text { rotic but large lumen vessels }\end{array}$ \\
\hline 3 & Lt mesial temporal lobe & 3 yrs & $\begin{array}{c}\text { Medically intractable seizures, rt } \\
\text { hemiparesis }\end{array}$ & $\begin{array}{c}\text { Sclerosis \& obliteration of most vessels; minority of sclerotic but } \\
\text { patent large lumen vessels }\end{array}$ \\
\hline 4 & Lt pons & 7 yrs & $\begin{array}{c}\text { Rt facial numbness, It CN VII palsy, rt } \\
\text { upper extremity paresis }\end{array}$ & $\begin{array}{c}\text { Sclerosis \& obliteration of most vessels; enlarging new small } \\
\text { vessels }\end{array}$ \\
\hline
\end{tabular}

$\mathrm{CN}=$ cranial nerve. 

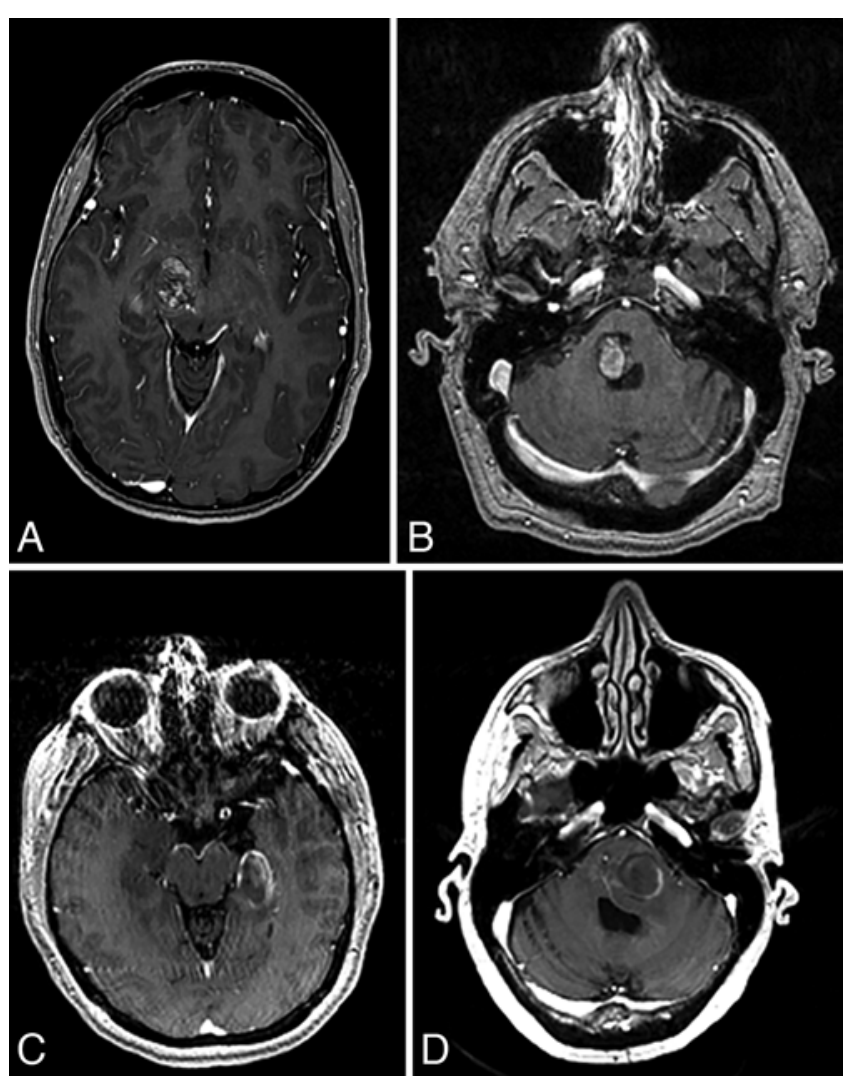

FIG. 1. Contrast-enhanced T1-weighted MR images showing a hemorrhagic $\mathrm{CM}$ in the right thalamus/midbrain in Case $1(\mathrm{~A})$, the right pons in Case 2 (B), the left mesial temporal lobe in Case $3(C)$, and the left pons in Case 4 (D).

Six months postoperatively, she had persistent but markedly improved left paresis.

\section{Histology and Immunohistochemistry}

$\mathrm{H} \&$ E-stained sections showed vascular sclerosis (Fig. 2A) and mineralization of vessels (Fig. 2B), but in some areas there were still numerous small vessels with thin fibrous walls according to trichrome stain (Fig. 2C). These vessels often stained positive for VEGF (Fig. 2D), whereas the sclerotic vessels did not. MMP-9 stained macrophages and showed diffuse staining in areas near these small vessels, but bFGF was negative. Hemosiderin from a previous hemorrhage was abundant, consistent with the patient's clinical history.

\section{Case 2}

\section{History and Examination}

A 31-year-old male presented with 2 pontine hemorrhages during an 18-month period. The bleeds resulted in a progressive left paresis, right abducens paresis, and diffuse left sensory loss involving the face, arm, and leg. Magnetic resonance imaging demonstrated a hemorrhagic lesion in the right aspect of the pons (Fig. 1B).

\section{Operation and Postoperative Course}

Stereotactic radiosurgery was performed: $30-G y$ maximum dose and 15-Gy margin dose delivered to a $2.8-\mathrm{cm}^{3}$ volume. Two and one-half years after SRS, the patient had worsening diplopia and new right-sided facial nerve palsy. Magnetic resonance imaging showed recurrent and progressive hemorrhagic enlargement of the pontine $\mathrm{CM}$. He underwent suboccipital craniectomy and had subtotal resection of the CM. Two months later, he continued to have persistent diplopia and facial weakness.

\section{Histology and Immunohistochemistry}

Examination of $\mathrm{H} \& \mathrm{E}$ and trichrome staining of the stereotactic biopsy specimen prior to SRS demonstrated ectatic back-to-back blood vessels characteristic of a CM (Fig. 3A). Resected CM tissue 2.5 years after SRS revealed incomplete vascular sclerosis and luminal narrowing (Fig. 3B). Vascular endothelial growth factor staining was weak, possibly because of cautery artifact. MMP-9 stained macrophages and showed diffuse staining in areas near these small vessels, but bFGF was negative.

\section{Case 3}

History and Examination

A 16-year-old epileptic female underwent partial resection of a left mesial temporal CM (Fig. 1C). Nine years later, when she was 25 years old, she presented with progressive right-sided weakness and uncontrolled partial seizures.

\section{Operation and Postoperative Course}

The residual CM was treated with Gamma Knife surgery: 30-Gy maximum dose and 15-Gy margin dose delivered to a $1-\mathrm{cm}^{3}$ volume. Three years later, the frequency of seizures again increased, and she underwent repeat resection via a pterional craniotomy. Postoperative confusion and right-sided weakness gradually resolved within 5 days. One year after surgery her seizures were reduced in frequency while on antiepileptic medication.

\section{Histology and Immunohistochemistry}

$\mathrm{H} \& \mathrm{E}$ and trichrome stains of the resected CM 3 years after SRS revealed many sclerosed vessels, which were sometimes accompanied by increased numbers of smaller vessels (Fig. 4A). Immunostaining for VEGF was light in these vessels (Fig. 4B), but the tissue showed severe cautery artifact as well. The presence of erythrocytes adjacent to the residual patent vessels suggested persistent microhemorrhage in the malformation despite the absence of MRI evidence of interval hemorrhage. There were also MMP-9-stained macrophages and diffuse staining of VEGF in areas near the vessels, but bFGF was negative.

\section{Case 4}

History and Examination

A 51-year-old female presented with a 1-week history of facial numbness, dizziness, and blurred vision. A CT scan demonstrated a left pontine hemorrhage from a CM. Repeat MRI indicated further hemorrhage.

\section{Operation and Postoperative Course}

The patient underwent clot evacuation via a suboccipital craniotomy. Since postoperative imaging demonstrated 

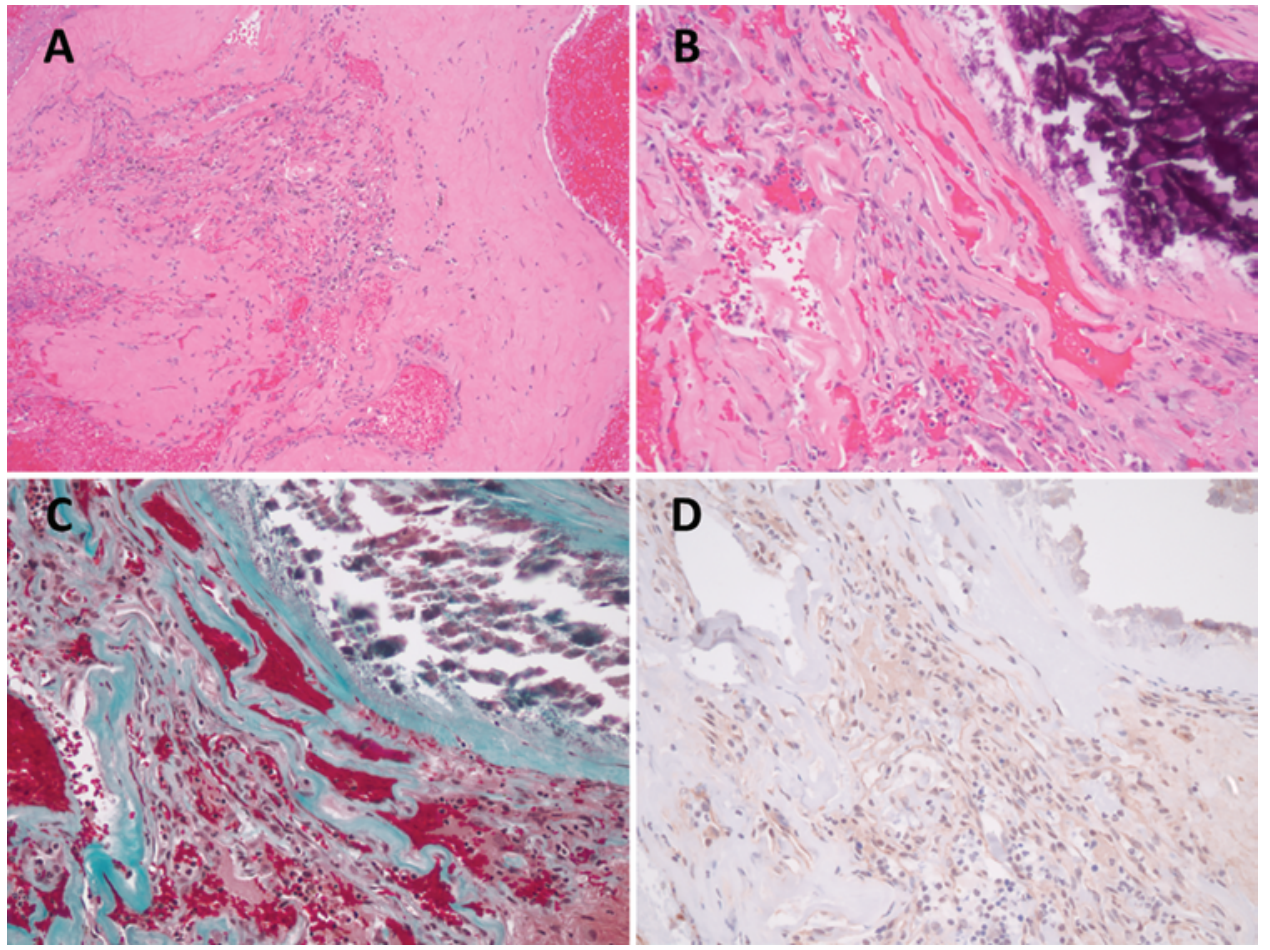

FIG. 2. Case 1. Photomicrographs obtained 4 months after SRS. Tissue sections show sclerotic vascular walls, mineralization, and areas with smaller vessels without sclerosis (A and B). Vessel walls $(C)$ and immunostaining positive for VEGF (D) are visible. H \& $E(A$ and $B)$ and trichrome $(C)$. Original magnification $\times 100(A)$ and $\times 200(B-D)$. Figure is available in color online only.

a residual $\mathrm{CM}$ she underwent Gamma Knife surgery 4 months later: 28-Gy maximum dose and 14-Gy margin dose delivered to a $0.65-\mathrm{cm}^{3}$ volume. She remained well until 7 years later, when she developed a new left-sided facial droop and right-sided facial numbness. Imaging studies demonstrated a new hemorrhage extending into the fourth ventricle (not shown in Fig. 1D). She underwent suboccipital craniotomy and resection of the entire CM.

\section{Histology and Immunohistochemistry}

$\mathrm{H} \&$ E-stained sections showed prominent vascular sclerosis with fibrinoid necrosis and hyalinization (Fig. 5A and C). Trichrome stains showed that most vessels were completely sclerotic, but focally there were dilated thin- walled vessels with little sclerosis (Fig. 5B) as well as robust staining for VEGF (Fig. 5D).

\section{Discussion \\ Rationale for SRS in CMs}

Previous publications have indicated that the risk of additional bleeds from repeatedly hemorrhagic CMs declines following SRS from as high as 50\% per year to $8 \%-$ $10 \%$ in the first 2 years to $1 \%-1.4 \%$ thereafter. ${ }^{1,5,13,18,19,21,24}$ Although Karlsson et al. ${ }^{11}$ have remained skeptical about the eventual bleeding risk protection of SRS, they noted a trend for a decreasing hemorrhage rate 4 years after SRS. They also noted that higher radiosurgical doses reduce the
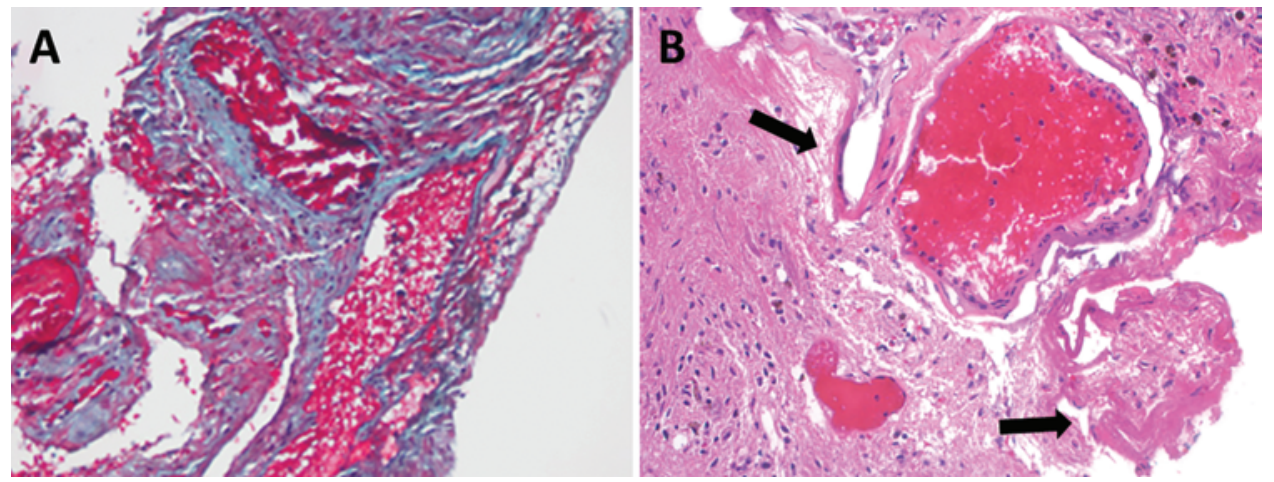

FIG. 3. Case 2. A: Trichrome staining of the CM tissue from the stereotactic needle biopsy showed back-to-back thin-walled vessels consistent with a CM. Original magnification $\times 200$. B: Two and a half years after SRS, the resected tissue showed some vessels with incomplete sclerosis (arrows), although many were partially or completely sclerosed. $\mathrm{H} \& \mathrm{E}$, original magnification $\times 100$. Figure is available in color online only. 

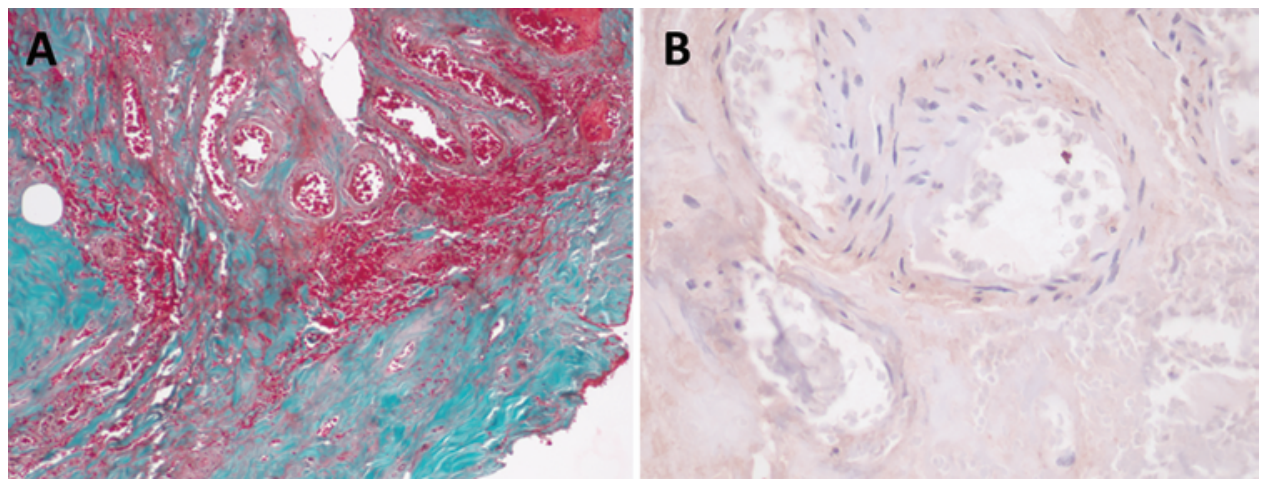

FIG. 4. Case 3. A: Trichrome stains show sclerosis of most vascular walls, but small vessels were present in one area. Original magnification $\times 100$. B: Although their morphology is suggestive of neovascularization, these vessels only stained lightly with VEGF, perhaps due to cautery artifact. Original magnification $\times 400$. Figure is available in color online only.

risk of posttreatment hemorrhage. This slow reduction in hemorrhage risk years indicates that the time course of SRS obliteration took years to complete. During this latency interval, CM patients can have recurrent hemorrhages. Since most patients with CM who undergo SRS have deep-seated malformations that have repeatedly bled, it is not surprising that relatively few histological studies have been reported. To further understand the potential reasons for recurrent hemorrhages despite SRS, we studied the histological findings in 4 patients who required resection of a CM because of repeated bleeds.

\section{Histological Response of Vascular Malformation Blood Vessels}

Stereotactic radiosurgery for AVMs results in progres- sive luminal thrombosis in response to endothelial proliferation, creation of intraluminal myofibroblasts, and hyalinization and sclerosis of the treated blood vessel walls. ${ }^{6,27,30,37}$ However, reports detailing the histopathological analysis of CMs after SRS are sparse. Authors of a few studies have claimed that CMs treated by SRS have several similarities to AVMs treated with SRS. ${ }^{23,32,34}$ Nyáry et al. showed vasculature obliteration in both AVMs and $\mathrm{CMs}^{23}$ as well as marked fibrosis of stromal tissue by 1 year after SRS. ${ }^{32}$ $\mathrm{Tu}$ et al. found that there were proteinaceous thrombi and hyalinized vessel walls in both AVMs and $\mathrm{CMs} ;{ }^{34}$ however, a notable difference was the near complete or complete occlusion of the AVMs but the partial occlusion of the CMs after SRS. Cavernous malformations after irradiation commonly had fibrinoid necrosis but patent vascular channels..$^{10}$
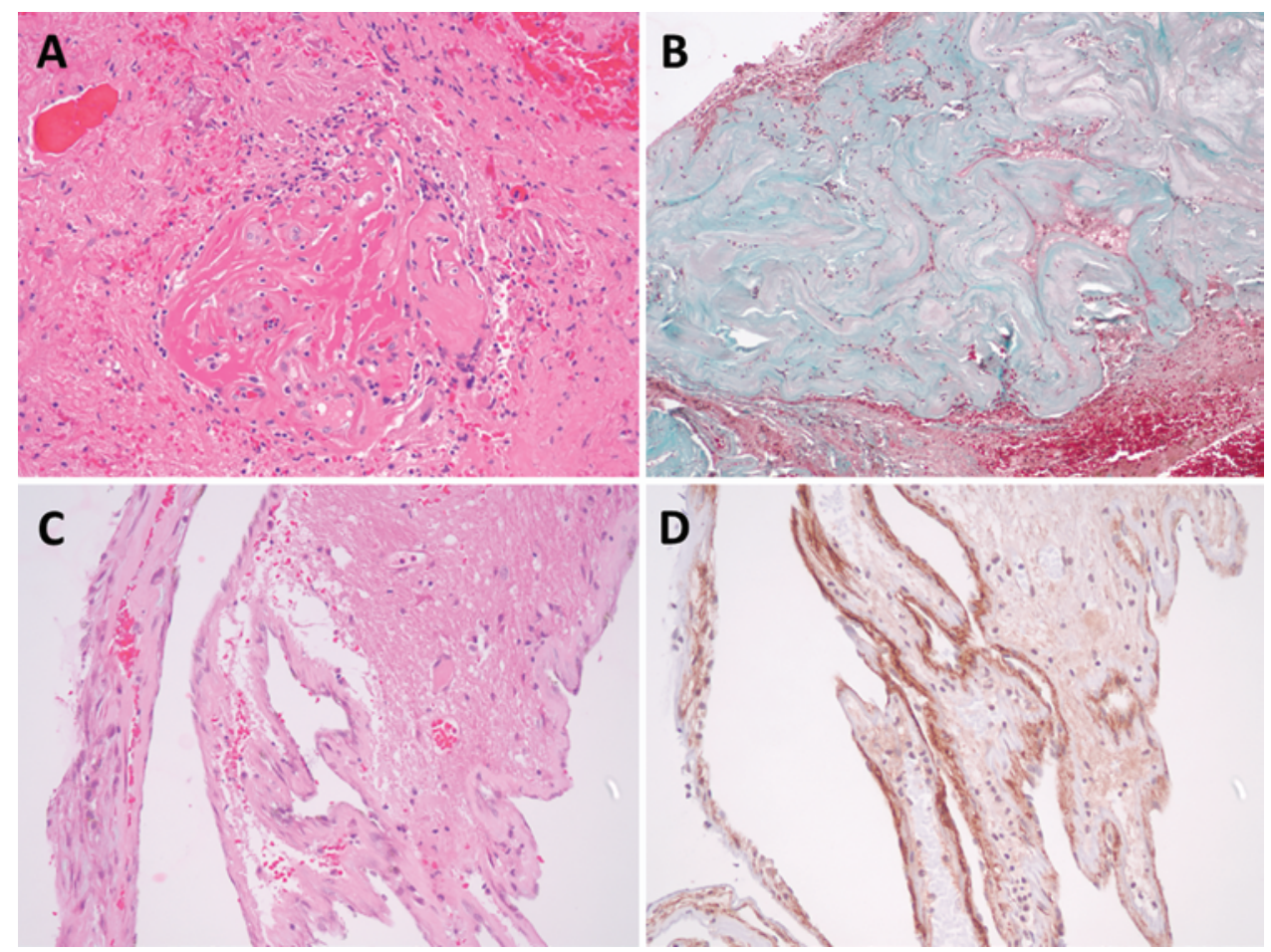

FIG. 5. Case 4. Seven years after SRS. Vascular sclerosis was prevalent with hyalinization (A) and complete obliteration of vascular lumen as seen by trichrome staining (B); however, thin-walled vessels were prominent in one area (C), and these vessels strongly stained for VEGF (D). Original magnification $\times 200$ (A) and ×100 (B-D). Figure is available in color online only. 
We detected partially obliterated vessels and wall sclerosis as early as 4 months after SRS. However, as may be suspected this soon after SRS, most of the vessels were not sclerosed. Such patent vessels are prone to hemorrhage until further sclerosis and obliteration occurs. In agreement with this finding, there is a higher hemorrhage risk within the first 2 years following SRS, as demonstrated in our previous studies. ${ }^{13,19,21}$ Obliterated vessels are found more commonly in histological samples from patients who have undergone surgery at 2.5 and 3 years after SRS. However, there are many larger vessels with sclerotic vascular walls but open lumen even at these time points. The lack of extensive vessel obliteration indicates that the patients are still at risk for hemorrhage from these large vessels. This finding is in agreement with our prior analysis demonstrating an annual rehemorrhage risk of $8.8 \%$ in the first 2 years and a decrease to $1.1 \%$ thereafter. ${ }^{13}$

By 7 years after SRS in the present study, most vessels were completely obliterated. However, these histological samples also demonstrated smaller patent vessels. These vessels had a wide range of diameters, and most showed no signs of sclerosis. Stereotactic radiosurgery leads to hyalinization of $\mathrm{CM}$ vessel walls, ${ }^{34}$ but these changes were not observed in small CM vessels with diameters on the order of capillaries and venules. Given that CMs proliferate via neoangiogenesis, ${ }^{31}$ we hypothesize that small diameter neovasculature developed after the original radiation (SRS) exposure. This initial neovascularization may progress to become the more characteristic thin-walled large-lumen vessels seen in typical CMs. Despite the early effect of radiation in altering vessel morphology, neovascularization as well as continuing enlargement of thin-walled vessels should be considered as a possible mechanism underlying rehemorrhage even as late as 7 years after radiosurgery.

Prominent endothelial cells can be commonly found in either granulation tissue or larger vessels after SRS, similar to the organizing thrombi and neovascularization reported in nonirradiated CM. ${ }^{28}$ The endothelial cells participating in neovascularization after irradiation have been previously studied in tumor xenograft models as well as ischemic injury models. Circulating endothelial progenitor cells from bone marrow have been shown to settle in areas of neovascularization and differentiate into endothelial cells. ${ }^{2,33}$ Although tumor and CM reactions to radiation may be different, these studies suggest that a possible source of endothelial cells are adjacent or circulating progenitor cells. With newly recruited endothelial cell progenitors, neovascularization may give rise to new vessels prone to hemorrhage.

A limitation of this study is the small number of samples. Among the 9 patients who had recurrent bleeding, only 5 cases were deemed appropriate for resection (1 case was excluded from the analysis because of inadequate tissue sample). The small number of cases may provide a selection bias since they are more serious bleeds resulting in medically intractable symptoms. In addition, the timeline for the evolution of CM is also inadequate since only samples from 4 months and 2.5, 3, and 7 years were found. Moreover, these samples are from different regions of the brain. However, a cautious conclusion of the effect of SRS was made through an analysis of various sections as well as immunostains for markers of neovascularization in this study.

\section{Conclusions}

In this study, all 4 post-SRS CM cases had incomplete sclerosis of blood vessels, indicating a possible cause of rebleeding. In 3 cases there were vascular changes suspicious for neovascularization, suggesting that such changes could also play a role in some cases of rebleeding. It is possible that SRS results in vascular sclerosis, but stromal components continue to produce angiogenic factors that promote neovascularization. However, the number of cases in this study is too small to be definitive and warrants future study with a larger number of cases.

\section{References}

1. Amin-Hanjani S, Ogilvy CS, Candia GJ, Lyons S, Chapman PH: Stereotactic radiosurgery for cavernous malformations: Kjellberg's experience with proton beam therapy in 98 cases at the Harvard Cyclotron. Neurosurgery 42:1229-1238, 1998

2. Asahara T, Masuda H, Takahashi T, Kalka C, Pastore C, Silver M, et al: Bone marrow origin of endothelial progenitor cells responsible for postnatal vasculogenesis in physiological and pathological neovascularization. Circ Res 85:221-228, 1999

3. Bergametti F, Denier C, Labauge P, Arnoult M, Boetto S, Clanet M, et al: Mutations within the programmed cell death 10 gene cause cerebral cavernous malformations. Am J Hum Genet 76:42-51, 2005

4. Bertalanffy H, Gilsbach JM, Eggert HR, Seeger W: Microsurgery of deep-seated cavernous angiomas: report of 26 cases. Acta Neurochir (Wien) 108:91-99, 1991

5. Chang SD, Levy RP, Adler JR Jr, Martin DP, Krakovitz PR, Steinberg GK: Stereotactic radiosurgery of angiographically occult vascular malformations: 14-year experience. Neurosurgery 43:213-221, 1998

6. Chang SD, Shuster DL, Steinberg GK, Levy RP, Frankel K: Stereotactic radiosurgery of arteriovenous malformations: pathologic changes in resected tissue. Clin Neuropathol 16:111-116, 1997

7. Davis DH, Kelly PJ: Stereotactic resection of occult vascular malformations. J Neurosurg 72:698-702, 1990

8. Del Curling O Jr, Kelly DL Jr, Elster AD, Craven TE: An analysis of the natural history of cavernous angiomas. J Neurosurg 75:702-708, 1991

9. Fahlbusch R, Strauss C, Huk W, Röckelein G, Kömpf D, Ruprecht KW: Surgical removal of pontomesencephalic cavernous hemangiomas. Neurosurgery 26:449-457, 1990

10. Gewirtz RJ, Steinberg GK, Crowley R, Levy RP: Pathological changes in surgically resected angiographically occult vascular malformations after radiation. Neurosurgery 42:738-743, 1998

11. Karlsson B, Kihlström L, Lindquist C, Ericson K, Steiner L: Radiosurgery for cavernous malformations. J Neurosurg 88:293-297, 1998

12. Kim DS, Park YG, Choi JU, Chung SS, Lee KC: An analysis of the natural history of cavernous malformations. Surg Neurol 48:9-18, 1997

13. Kondziolka D, Lunsford LD, Flickinger JC, Kestle JR: Reduction of hemorrhage risk after stereotactic radiosurgery for cavernous malformations. J Neurosurg 83:825-831, 1995

14. Kondziolka D, Lunsford LD, Kestle JR: The natural history of cerebral cavernous malformations. J Neurosurg 83:820824, 1995

15. Kondziolka D, Monaco EA III, Lunsford LD: Cavernous 
malformations and hemorrhage risk. Prog Neurol Surg 27:141-146, 2013

16. Laberge-le Couteulx S, Jung HH, Labauge P, Houtteville JP, Lescoat C, Cecillon M, et al: Truncating mutations in CCM1, encoding KRIT1, cause hereditary cavernous angiomas. Nat Genet 23:189-193, 1999

17. Laurans MS, DiLuna ML, Shin D, Niazi F, Voorhees JR, Nelson-Williams C, et al: Mutational analysis of 206 families with cavernous malformations. J Neurosurg 99:38-43, 2003

18. Liu KD, Chung WY, Wu HM, Shiau CY, Wang LW, Guo WY, et al: Gamma knife surgery for cavernous hemangiomas: an analysis of 125 patients. J Neurosurg 102 Suppl: 81-86, 2005

19. Lunsford LD, Khan AA, Niranjan A, Kano H, Flickinger JC, Kondziolka D: Stereotactic radiosurgery for symptomatic solitary cerebral cavernous malformations considered high risk for resection. J Neurosurg 113:23-29, 2010

20. Mathiesen T, Edner G, Kihlström L: Deep and brainstem cavernomas: a consecutive 8-year series. J Neurosurg 99:3137, 2003

21. Monaco EA, Khan AA, Niranjan A, Kano H, Grandhi R, Kondziolka D, et al: Stereotactic radiosurgery for the treatment of symptomatic brainstem cavernous malformations. Neurosurg Focus 29(3):E11, 2010

22. Moriarity JL, Wetzel M, Clatterbuck RE, Javedan S, Sheppard JM, Hoenig-Rigamonti K, et al: The natural history of cavernous malformations: a prospective study of 68 patients. Neurosurgery 44:1166-1173, 1999

23. Nyáry I, Major O, Hanzély Z, Szeifert GT: Pathological considerations to irradiation of cavernous malformations. Prog Neurol Surg 20:231-234, 2007

24. Pollock BE, Garces YI, Stafford SL, Foote RL, Schomberg PJ, Link MJ: Stereotactic radiosurgery for cavernous malformations. J Neurosurg 93:987-991, 2000

25. Porter RW, Detwiler PW, Spetzler RF, Lawton MT, Baskin JJ, Derksen PT, et al: Cavernous malformations of the brainstem: experience with 100 patients. J Neurosurg 90:50-58, 1999

26. Robinson JR, Awad IA, Little JR: Natural history of the cavernous angioma. J Neurosurg 75:709-714, 1991

27. Schneider BF, Eberhard DA, Steiner LE: Histopathology of arteriovenous malformations after gamma knife radiosurgery. J Neurosurg 87:352-357, 1997

28. Scott RM, Barnes P, Kupsky W, Adelman LS: Cavernous angiomas of the central nervous system in children. J Neurosurg 76:38-46, 1992

29. Steinberg GK, Chang SD, Gewirtz RJ, Lopez JR: Microsurgical resection of brainstem, thalamic, and basal ganglia an- giographically occult vascular malformations. Neurosurgery 46:260-271, 2000

30. Steinberg GK, Chang SD, Levy RP, Marks MP, Frankel K, Marcellus M: Surgical resection of large incompletely treated intracranial arteriovenous malformations following stereotactic radiosurgery. J Neurosurg 84:920-928, 1996

31. Sure U, Butz N, Schlegel J, Siegel AM, Wakat JP, Mennel HD, et al: Endothelial proliferation, neoangiogenesis, and potential de novo generation of cerebrovascular malformations. J Neurosurg 94:972-977, 2001

32. Szeifert GT, Levivier M, Lorenzoni J, Nyáry I, Major O, Kemeny AA: Morphological observations in brain arteriovenous malformations after gamma knife radiosurgery. Prog Neurol Surg 27:119-129, 2013

33. Takahashi T, Kalka C, Masuda H, Chen D, Silver M, Kearney $\mathrm{M}$, et al: Ischemia- and cytokine-induced mobilization of bone marrow-derived endothelial progenitor cells for neovascularization. Nat Med 5:434-438, 1999

34. Tu J, Stoodley MA, Morgan MK, Storer KP, Smee R: Different responses of cavernous malformations and arteriovenous malformations to radiosurgery. J Clin Neurosci 16:945-949, 2009

35. Tung H, Giannotta SL, Chandrasoma PT, Zee CS: Recurrent intraparenchymal hemorrhages from angiographically occult vascular malformations. J Neurosurg 73:174-180, 1990

36. Wang CC, Liu A, Zhang JT, Sun B, Zhao YL: Surgical management of brain-stem cavernous malformations: report of 137 cases. Surg Neurol 59:444-454, 2003

37. Yen CP, Schlesinger D, Sheehan JP: Natural history of cerebral arteriovenous malformations and the risk of hemorrhage after radiosurgery. Prog Neurol Surg 27:5-21, 2013

\section{Author Contributions}

Conception and design: Friedlander, Shin, Murdoch, Lunsford. Acquisition of data: Shin, Hamilton, Kano. Analysis and interpretation of data: Friedlander, Shin, Murdoch, Hamilton, Faraji, Kano, Lunsford. Drafting the article: Shin, Hamilton, Zwagerman, Gardner. Critically revising the article: Friedlander, Shin, Hamilton, Faraji, Kano, Zwagerman, Gardner, Lunsford. Reviewed submitted version of manuscript: Friedlander, Shin, Hamilton, Lunsford. Study supervision: Friedlander, Murdoch.

\section{Correspondence}

Robert M. Friedlander, Department of Neurological Surgery, University of Pittsburgh Medical Center, UPMC Presbyterian, 200 Lothrop St., Ste. B-400, Pittsburgh, PA 15213. email: friedlanderr@upmc.edu. 